\title{
Electrochemical Behaviour of Titanium-Bearing Slag Relevant for Molten Oxide Electrolysis
}

\author{
Samuel Martin-Treceno ${ }^{a}$, Nicholas Weaver $^{a}$, Antoine Allanore ${ }^{c}$, Catherine M. Bishop ${ }^{b}$, Aaron \\ T. Marshall ${ }^{a, *}$ and Matthew J. Watson ${ }^{a}$ \\ ${ }^{a}$ Department of Chemical and Process Engineering, University of Canterbury, Christchurch, New Zealand \\ ${ }^{b}$ Department of Mechanical Engineering, University of Canterbury, Christchurch, New Zealand \\ ${ }^{c}$ Department of Materials Science and Engineering, Massachusetts Institute of Technology, Cambridge, Massachusetts 02139, USA
}

\section{ARTICLE INFO}

\section{Keywords:}

ultra-high-temperature electrochem-

istry

molten oxide electrolysis

electrolyte characterization

iridium alloys

\begin{abstract}
A B S T R ACT
A containerless approach was used to investigate the electrochemical behaviour of $\mathrm{TiO}_{2}-\mathrm{SiO}_{2}-$ $\mathrm{Al}_{2} \mathrm{O}_{3}-\mathrm{MgO}-\mathrm{CaO}$ slags in their molten state. Iridium was used in a three-electrode configuration to perform a combination of electrochemical techniques inside a modified thermal imaging furnace. The real-time visualisation during experimentation and the post-mortem microscopy analysis confirmed the direct production of an $\mathrm{Ir}-\mathrm{Ti}-\mathrm{Si}$ alloy and the evolution of oxygen during electrolysis. Thermodynamic properties of the slag were predicted with FactSage and were consistent with experiment. The results justify the use of this method to better characterize the potential of these systems as a secondary source of materials.
\end{abstract}

\section{Introduction}

The electrolysis of molten metal oxide feedstocks has been proposed as a more sustainable and environmentally friendly alternative to the conventional extractive metallurgical processes [1]. This method is commonly referred to as molten oxide electrolysis (MOE). MOE uses electrons as the reducing agent to separate metals from molten oxide electrolytes. One key feature of this process is that oxygen can be the only by-product generated if the counter electrode (CE) material is inert at the operating conditions [2]. Provided the electricity is generated from renewable resources, the implementation of MOE can contribute to decarbonization of the metallurgical sector.

The success of using electricity to extract any metal from its ore relies upon finding an appropriate supporting electrolyte. A profound understanding of the physical-chemical properties of the electrolyte in its molten state is then crucial to the development of this technique. However, the high melting points of most oxides have traditionally imposed very demanding material constraints making it extremely challenging to study them at a laboratory scale. Traditionally, crucibles have been used to place the oxide melts under study in the hot zone of a furnace. The containment compatibility issues (i.e. slag / crucible interaction [3]) derived from the use of this type of furnace have limited the thermodynamic data available. The larger the number of constituent elements in the melt, the scarcer the data. Characterizing the properties of the candidate molten oxide electrolytes remains a major challenge for MOE [4].

The push for green electrification and decarbonization of industrial processes brought attention to the application of MOE in steelmaking [5]. Steel is the most widely used alloy in the world with a yearly production of 1.8 billion tons [6]. For each ton of steel produced, 1.83 tons of $\mathrm{CO}_{2}$ are produced [7], which makes steelmaking one of the largest industrial source of the greenhouse gas. Research in this field has been mainly focused on the extraction of iron from $\mathrm{FeO}_{x}$ containing melts [7-10]. For the more complex, chemically-aggressive, Ti-bearing oxide melts, such as $\mathrm{TiO}_{2}-\mathrm{SiO}_{2}-\mathrm{Al}_{2} \mathrm{O}_{3}-\mathrm{MgO}-\mathrm{CaO}$ slags, thermodynamic data is only available for narrow ranges of temperature and composition [11]. However, in countries like China and New Zealand, these slags are available as by-products of the local steelmaking processes, and can contain more than $30 \mathrm{wt} . \% \mathrm{TiO}_{2}$ [12]. The slag is tapped at temperatures above $1700 \mathrm{~K}$, dumped to cool, crushed and sold as an aggregate for cement production or fill for roading. This practice is a waste of titanium resources and sensible heat, which constitutes around $10 \%$ of the waste energy of the steel industry [13]. With the universal need to improve resource efficiency and mainstream sustainability practices [14],

@aaron.marshall@canterbury.ac.nz (A.T. Marshall)

ORCID(s): 0000-0002-3530-7251 (A.T. Marshall) 

pressed at $300 \mathrm{MPa}$ for 5 minutes.

\subsection{Thermodynamic Predictions} $\left(T_{\text {sol }}\right)$, were determined. These values are given in Table 1.

$$
\mathrm{TiO}_{2}+4 \mathrm{e}^{-} \longrightarrow \mathrm{Ti}+2 \mathrm{O}^{2-}
$$
(98\%, CARLO ERBA Reagents), $\mathrm{TiO}_{2}$ (99.9\%, CERAC Inc.), $\mathrm{CaCO}_{3}$ (99.95\%, CERAC Inc.), $\mathrm{SiO}_{2}(99.4 \%$, CARLO ERBA Reagents) and $\left(\mathrm{MgCO}_{3}\right)_{4} \cdot \mathrm{Mg}(\mathrm{OH})_{2} \cdot 5 \mathrm{H}_{2} \mathrm{O}(99 \%$, SIGMA-ALDRICH) as starting materials. Approximately $100 \mathrm{~g}$ of the mixed powders were weighed into high-density polyethylene bottles and ball mill blended overnight in EtOH with $\mathrm{ZrO}_{2}$ milling balls on a rotating roller mill. The powder was recovered using rotary evaporation, dried, then granulated through a coarse sieve. Granulated blended batch materials were fired in air at $1873 \mathrm{~K}$ in a platinum crucible and furnace cooled. The resulting solid was reheated in a platinum crucible to $1473 \mathrm{~K}$ and water quenched. The recovered material was micronized, placed into latex balloons (Pioneer Balloon Co.) and cold hydrostatically

Thermodynamic properties were calculated for slags using the thermodynamic software FactSage 7.2. Model parameters are from FToxid and FactPS databases [18]. For each slag composition at a total pressure of $1 \mathrm{~atm}$, the phase relations as a function of temperature were predicted. The maximum temperature for any solid phase to be stable, the liquidus temperature $\left(T_{l i q}\right)$, and the minimum temperature for any liquid phase to be stable, the solidus temperature

The thermodynamic cell voltages required to deposit metals from the molten slag were calculated in the following manner. For brevity only the example for Ti deposition is given. The cathodic reaction was first assumed to be: 
Table 1

Thermodynamic properties predicted for the electrolyte compositions investigated in ascending order of their predicted $T_{l i q} . E_{\text {cell }, \mathrm{TiO}_{2}}$ is the cell voltage for Reaction 3 at $1903 \mathrm{~K}$.

\begin{tabular}{l|ccccc|cc|cc}
\hline & $\begin{array}{c}\mathrm{TiO}_{2} \\
\text { wt. } \%\end{array}$ & $\begin{array}{c}\mathrm{CaO} \\
\text { wt. } \%\end{array}$ & $\begin{array}{c}\mathrm{SiO}_{2} \\
\text { wt. } \%\end{array}$ & $\begin{array}{c}\mathrm{Al}_{2} \mathrm{O}_{3} \\
\text { wt. } \%\end{array}$ & $\begin{array}{c}\mathrm{MgO} \\
\text { wt. } \%\end{array}$ & $\begin{array}{c}T_{\text {sol }} \\
\mathrm{K}\end{array}$ & $\begin{array}{c}T_{\text {liq }} \\
\mathrm{K}\end{array}$ & $\begin{array}{c}E_{\text {cell, } \mathrm{SiO}_{2}} \\
\mathrm{~V}\end{array}$ & $\begin{array}{c}E_{\text {cell, } \mathrm{TiO}_{2}} \\
\mathrm{~V}\end{array}$ \\
\hline Slag A & 33 & 18 & 15 & 19 & 15 & 1486 & 1803 & -1.61 & -1.65 \\
Slag B & 15 & 24 & 25 & 18 & 18 & 1494 & 1823 & -1.63 & -1.72 \\
Slag C & 9 & 25 & 26 & 20 & 19 & 1494 & 1883 & -1.66 & -1.75 \\
Slag D & 21 & 21 & 11 & 26 & 21 & 1615 & 1960 & -1.69 & -1.73 \\
\hline
\end{tabular}

The anodic reaction was then assumed to be:

$$
2 \mathrm{O}^{2-} \longrightarrow \mathrm{O}_{2}+4 \mathrm{e}^{-}
$$

Thus the full cell reaction was:

$$
\mathrm{TiO}_{2} \longrightarrow \mathrm{Ti}+\mathrm{O}_{2}
$$

While the overall Gibbs energy change for Reaction 3 is independent of mechanism, the cell voltage for Reaction 3 will depend on pathway and thus should be treated as an indicative value only. At standard conditions and the temperature of interest, the cell voltage, $E_{c e l l}^{\circ}$, was then determined by:

$$
E_{c e l l}^{\circ}=\frac{\Delta G^{\circ}}{-n F}
$$

where $\Delta G^{\circ}$ is the standard Gibbs energy of dissociation for Reaction 3, $n=4$ is the number of electrons involved in the reaction, and $F$ is the Faraday constant. $\Delta G^{\circ}$ for the full cell reaction was obtained at the temperature of interest from FactSage. At $1903 \mathrm{~K}$, the standard cell voltage for Reaction 3, $E_{\text {cell, } \mathrm{TiO}_{2}}^{\circ}$, is $-1.56 \mathrm{~V}$. However, as the system under the examined conditions is not at standard conditions, the cell voltage $\left(E_{c e l l}\right)$ is calculated from the Nernst equation:

$$
E_{\text {cell }}=E_{\text {cell }}^{\circ}-\frac{R T}{n F} \cdot \ln \frac{\prod a_{\text {products }}^{v}}{\prod a_{\text {reactants }}^{v}}
$$

where $R$ is the universal gas constant, $T$ is the temperature of interest, $v$ are the stoichiometric coefficients and $a_{i}$ are the activities of the species present in the reaction. To account for the non-ideal properties of the molten slag system, the activity of $\mathrm{TiO}_{2}$ in the melt, $a_{\mathrm{TiO}_{2}}$, at $T$ was calculated from FactSage. Unit activity was chosen for titanium metal as it was assumed that pure solid metal will be produced. All the $v$ of the reaction quotient are 1 (see Reaction 3 ). Since the pressure inside the furnace was low, and $1 \mathrm{~atm}$ pure $\mathrm{O}_{2}$ gas was chosen as the standard state of the oxygen gas at the $\mathrm{CE}$, the partial pressure of oxygen was assumed equal to the activity of oxygen. The $P_{\mathrm{O}_{2}}$ is 1 atm as dissolved $\mathrm{O}_{2}$ is assumed in equilibrium with pure $\mathrm{O}_{2}$ bubbles evolved at the counter electrode. The cell voltages for $\mathrm{Si}$ and Ti metal deposition were calculated according to Equation 6, and is reported in Table 1.

$$
E_{c e l l, \mathrm{TiO}_{2}}=E_{\text {cell, }, \mathrm{TiO}_{2}}^{\circ}-\frac{R T}{4 F} \cdot \ln \frac{1}{a_{\mathrm{TiO}_{2}}}
$$

\subsection{Phase Relations Determination}

Differential scanning calorimetry (DSC) and X-ray powder diffraction (XRD) techniques were utilized to validate thermodynamic predictions. Heat flow measurements were performed (NETZSCH STA 449 F3 Jupiter) under an argon atmosphere $\left(120 \mathrm{~mL} \mathrm{~min}^{-1}, 99.999 \%\right)$. Platinum crucibles with a lid were used to contain about $10 \mathrm{mg}$ of slag which was thermally cycled at $20 \mathrm{~K} \mathrm{~min}^{-1}$ up to $1873 \mathrm{~K}$. An alumina spacer was used to protect the sensor from the crucible when operating at temperatures above $1673 \mathrm{~K}$. In situ XRD analysis of slag was conducted at the Australian Synchrotron using the powder diffraction beamline. The samples were mounted in a $0.1 \mathrm{~mm}$ deep rebate in a platinum strip element in an Anton Paar Furnace. Diffractograms were measured every 60 seconds as the samples were heated 
from $1500 \mathrm{~K}$ to $1873 \mathrm{~K}$ at $5 \mathrm{~K} \mathrm{~min}^{-1}$. The $\mathrm{X}$-ray energy was set at $11 \mathrm{keV}$ and the diffraction data acquired using a Mythen 1D detector between 10 and 85 degrees $2 \theta$.

\subsection{Furnace Operation}

The use of the pendant droplet technique in a modified thermal imaging furnace (TX-12000-I-MIT-VPO-PC, Crystal Systems Corp.) to carry out electrochemical measurements has been described before [17, 19, 20]. Briefly, at the beginning of each experiment, a cylindrical sample was suspended from the upper furnace shaft inside a quartz tube (Technical Glass Products Inc.). The sintered electrolyte samples were 5 to $7 \mathrm{~mm}$ in diameter and 60 to $80 \mathrm{~mm}$ in length, and sample position was controlled using a stepper motor with submillimeter precision. Vacuum was applied to certify that there were no leaks in the system. The quartz tube containing the electrochemical cell was then purged three times before turning on the furnace. UHP Ar (99.999\%, Airgas Inc.) was used to refill the chamber and during operation with a flow rate of $200 \mathrm{~mL} \mathrm{~min}^{-1}\left(P_{\mathrm{O}_{2}}=10^{-6} \mathrm{~atm}\right)$. The operating temperature was determined by contacting the molten droplet with a thermocouple. $\mathrm{W}-\operatorname{Re}(5 \mathrm{wt} . \%) \mid \mathrm{W}-\operatorname{Re}(26 \mathrm{wt} . \%)$ thermocouples (type C) were used, with $\mathrm{a} \pm 1 \%$ maximum error at the operating temperatures.

Once the operating temperature (i.e. furnace lamp power) was chosen, the sample was lowered until its bottom end was in the hot zone and it was rotated until a stable pendant droplet was formed. Then, the three iridium wire electrodes ( $\mathrm{Ir}>99.9 \%$, diameter $=0.5 \mathrm{~mm}$, Furuya Metals Co., Ltd.), held inside an $\mathrm{Al}_{2} \mathrm{O}_{3}$ four-bore tube, were raised up while monitoring the open circuit potential (OCP). A sudden change in the OCP, and in situ visualization, confirmed that the electrodes had contacted the molten droplet. Once the electrodes had made contact with the molten droplet, the wires were raised further into the molten droplet to an immersion depth of approximately $2 \mathrm{~mm}$. See reference [17] for details regarding the assembly of the iridium electrodes and electrical connections to the potentiostat. An image of the electrochemical cell configuration is shown in Figure 1. The image was captured through a flat window in the quartz tube by a camera (EOS Rebel T5i DSLR, Canon Inc.) with telescopic lens during operation at $1903 \mathrm{~K}$.

\subsection{Electrochemical Measurements and Analysis}

Iridium wires were employed as the working (WE), counter and pseudo-reference electrodes. Iridium was chosen as the electrode material as it satisfied the technical requirements of being solid at the operating temperatures (melting point $=2179 \mathrm{~K}$ ) and mechanically robust enough (elastic modulus $=528 \mathrm{GPa}$ at room temperature) to insert a thin wire into the molten slag repeatedly. Tungsten and molybdenum also met the requirements and are cheaper, but, unlike iridium, they are susceptible to oxidation under the given experimental conditions. Initial experiments found that Mo and $\mathrm{W}$ wires were not stable during electrolysis as the oxygen gas that evolved at the counter electrode (which is very close to the other electrodes in the pendant droplet configuration, see Figure 1) quickly reacted with these metals and formed volatile metal oxide phases leading to severe corrosion. The melting points of silicon, iron and platinum make them unsuitable for this application. The use of carbon is avoided due to the likelihood of a carbothermal reaction with $\mathrm{Ti}$ or Si to form carbides [21]. Other high melting point metals such as titanium and zirconium are not chemically stable in the slag as they can reduce metals from oxide species within the melt. Iridium has been intensively studied in MOE [7, 17, 19, 22], where it has been demonstrated to act as an oxygen-evolving anode [7]. While the price of iridium is too high for large-scale applications, iridium plays an important role in laboratory scale studies.

In this work, the pseudo-reference electrode consisted of an iridium wire immersed into the molten slag droplet. This type of reference electrode is commonly used in MOE when performing three-electrode measurements [7, 9, 17, 19, 22], where it provides a constant potential and has the advantage of having a low impedance [23]. However, its potential cannot be calculated thermodynamically as the species in equilibrium at the pseudo-reference electrode are unknown. All the potentials measured are referred to this pseudo-reference electrode, which was found to be stable throughout multiple measurements. While some have successfully used oxide / oxygen reference electrodes based on solid $\mathrm{ZrO}_{2}$ electrolyte separators [10], in this system, the small size of the molten oxide droplet limits the ability to use this type of reference electrode. Furthermore, as $\mathrm{ZrO}_{2}$ is soluble in this oxide melt [24], using this type of reference electrode would contaminate the system. An alternative approach is to use metal / metal oxide reference electrodes, which are essentially metal wires coated in a thin oxide layer [25]. While these have proved useful in some systems, the electrode material constraints stated above made these unsuitable for this study. 
All the electrochemical measurements were conducted using a potentiostat (Gamry Reference 3000). The OCP was recorded to begin each measurement. The ohmic resistance between the working and pseudo-reference electrodes was calculated from electrochemical impedance spectroscopy measurements at OCP. The distance between both electrodes was approximately $2 \mathrm{~mm}$. For each experiment, the value was obtained at high frequency when the phase angle was close to zero. A typical resistance value was $1.5 \Omega$. To account for the ohmic drop, $70 \%$ of this value was applied for positive feedback and the remaining $30 \%$ used for post-run $I R$ correction. Cyclic voltammetry (CV) was used to determine the potential scan range and to identify the presence of redox couples within the electrolyte. Potentiostatic electrolysis experiments were performed to confirm the peak identified with the CV measurements.

Following the experiment, the quenched droplet was cross-sectioned from the remaining unmolten rod using a low speed diamond saw (Bühler). The sample was polished down to $1 \mu \mathrm{m}$ using a diamond suspension over abrasive pads. The microstructure and morphology of the product were observed using a scanning electron microscope (SEM, JEOL IT-300) equipped with an energy dispersive spectrometer (EDS).

\section{Results and Discussion}

\subsection{Validating Thermodynamic Predictions}

The thermodynamic predictions reported in Table 1 were validated by comparing the calculated $T_{\text {sol }}$ with those determined by DSC, and the calculated $T_{l i q}$ with in situ XRD analysis. For Slag C, the $T_{\text {sol }}$ was predicted to be $1494 \mathrm{~K}$. The onset of the first endothermic peak detected in the heating path was used as a proxy for $T_{\text {sol }}$ in the DSC measurements. The experimental solidus was $1488 \mathrm{~K}$, which is consistent with the prediction. The $T_{\text {liq }}$ was difficult to determine via DSC due to the decrease in sensitivity at very high temperatures, possibly aggravated by the use of a spacer [26]. In situ XRD, was used for further validation of thermodynamic predictions. FactSage predicted that the last stable solid phase would be magnesium aluminium spinel with nominal composition $\mathrm{MgAl}_{2} \mathrm{O}_{4}$. Indeed, on heating to the maximum experimentally achievable temperature $(1873 \mathrm{~K})$ the only crystalline phase present was the spinel. Complete melting at the maximum operating temperature of the in situ XRD heater $(1873 \mathrm{~K})$ was not observed for Slag C, which is consistent with the liquidus temperature prediction (1883 K) for this composition. Taken together, the DSC and XRD measurements validate the use of thermochemical data from FactSage for the complex, pseudo-quinary slag phase and support its use for reaction potentials in this composition space.

\subsection{Cyclic Voltammetry}

The influence of the lower potential limit during $\mathrm{CV}$ was investigated (Figure 2). The scan rate was set to $1 \mathrm{~V}$ $\mathrm{s}^{-1}$ to mitigate the effect of the interaction between the metallic product and the WE. A slower scan rate would allow more time at reducing conditions, which could affect the dimensional stability of the WE. The potential was scanned from $0.5 \mathrm{~V}$ vs Ir towards negative potentials for three cycles. The upper potential limit was set at $0.5 \mathrm{~V}$, as above this potential, the voltammograms became less reproducible, possibly because of the onset of the oxygen evolution reaction (gas bubbles could be observed at $0.7 \mathrm{~V}$ vs Ir).

The negative potential scan limit was shifted to more negative values for each curve in Figure 2 in steps of - 100 $\mathrm{mV}$ (from $0 \mathrm{~V}$ to $-0.6 \mathrm{~V}$ ). Decreasing the lower potential limit towards more negative potentials resulted in the cathodic current becoming more negative. Each curve corresponds to the third cycle of an individual CV measurement for Slag $\mathrm{C}$, where the features of the $\mathrm{CV}$ were reproducible from cycle to cycle. The $\mathrm{CV}$ is not reproducible when the lower potential limit is below $-0.6 \mathrm{~V}$. This may be due to changes in WE shape / area due to metal deposition and slag droplet disturbances caused by the gas bubbles generated at the CE. Based on the potential at which oxygen evolution reaction was observed $(0.7 \mathrm{~V}$ vs Ir) and the potential for the cathodic metal deposition $(-0.6 \mathrm{~V}$ vs Ir), the overall cell voltage was estimated to be $-1.3 \mathrm{~V}$. This is lower than the predicted cell voltages required for Si and Ti deposition from Slag $\mathrm{C}$ at $1903 \mathrm{~K}$, which are $-1.66 \mathrm{~V}$ and $-1.75 \mathrm{~V}$, respectively (see Table 1). This is possibly due to the underpotential deposition of $\mathrm{Ti}$ and $\mathrm{Si}$ on the Ir WE. It seems unlikely that two reduction events would be observed as there is less than $100 \mathrm{mV}$ between the predicted cell voltages.

The effect of slag composition on the cyclic voltammograms was investigated (Figure 3). For all measurements, 
the potential was swept in the negative direction until $-0.5 \mathrm{~V}$ vs Ir, and it was found that the current density increased with the concentration of $\mathrm{TiO}_{2}$. This is consistent with thermodynamic predictions using FactSage (Table 1). Slag A has the most positive predicted $E_{\text {cell, } \mathrm{TiO}_{2}},-1.65 \mathrm{~V}$, compared with the least positive $-1.75 \mathrm{~V}$ for Slag C. For a process involving the cathodic deposition of a metal, the cathodic current density increases as the potential becomes more negative. For all slags, the increase in the cathodic current density is consistent with the increase in the concentration of $\mathrm{TiO}_{2}$. Interestingly, the concentration of $\mathrm{SiO}_{2}$ seems to have little effect, where no clear trend was found. However, based on the thermodynamic predictions, the reduction of $\mathrm{Si}$ from $\mathrm{SiO}_{2}$ is thermodynamically more favourable than Ti from $\mathrm{TiO}_{2}$.

\subsection{Potentiostatic Electrolysis}

Potentiostatic electrolysis experiments were performed to confirm the electrochemical deposition of metals and to investigate whether the shape of the CVs could be attributed to phenomena occurring after the electron transfer reaction. The current density during electrolysis of Slag D $\left(21 \mathrm{wt} . \% \mathrm{TiO}_{2}\right)$ was quite noisy (Figure 4). Kim et al. [27] associated the spikes in the signal recorded during electrolysis to an increase in the electrical resistivity caused by large bubble formation in the electrolyte. Similarly, in this system, the number of gas bubbles formed was such that they interfered in the electrical connection between the electrodes and the molten sample. Bubbling began as soon as potential was applied to the cell. The bubbles evolved at the CE were observed to disturb the shape of the molten droplet which would have altered the length of WE wire inserted into the droplet, and thus altered the current. The current density value in Figure 4 assumes a constant WE area.

After 300 seconds the lamps of the thermal imaging furnace were shut off, quenching the electrodes inside the droplet prior to terminating the experiment. SEM observations of the polished cross-section after electrolysis are presented in Figure 5. The Ir WE surface was noticeably modified (Figure 5A). The area of the pure iridum WE decreased slightly. As a result of the electrolysis, the remaining Ir is part of an alloy that had formed around the surface of the WE. EDS compositional analysis indicated that it was an oxide-free $\mathrm{Ir}-\mathrm{Ti}-\mathrm{Si}$ region. This shows unequivocally that $\mathrm{Ti}$ and $\mathrm{Si}$ were reduced from the slag during the experiment. Along that deposited layer, three regions with different Z-contrast were identified (Figure 5B). The composition of each phase was determined from five EDS spot measurements from different regions of each phase. The ranges of normalised atomic compositions are given by $\mathrm{Ir}_{0.29-0.40} \mathrm{Ti}_{0.32-0.42} \mathrm{Si}_{0.26-0.30}$ (dark grey), $\mathrm{Ir}_{0.48-0.50} \mathrm{Ti}_{0.32-0.34} \mathrm{Si}_{0.17-0.18}$ (medium grey) and $\mathrm{Ir}_{0.65-0.69} \mathrm{Ti}_{0.31-0.35}$ (light grey). The light grey Ir-Ti phase has a composition between the reported TiIr and TiIr $_{3}$ intermetallics [28].

Thermodynamically, Si reduction from the melt was predicted to be the most favourable, which could suggest that $\mathrm{Si}$ would be preferentially deposited. However, based on the EDS compositional analysis, the Ti content in the different alloy phases is always larger than that of $\mathrm{Si}$. This suggest that $\mathrm{Si}$ may not be reduced from $\mathrm{SiO}_{2}$, but it may be reduced from a more stable complex or ion, which explains the lack of a clear trend with $\mathrm{SiO}_{2}$ concentration in Figure 3. Nakanishi and Allanore [19] reported that a non-ideal mixing behaviour in the molten state for the $\mathrm{La}_{2} \mathrm{O}_{3}-\mathrm{Y}_{2} \mathrm{O}_{3}$ mixture led to selective extraction of La, contradicting simple thermodynamic predictions. Further research needs to address the non-ideal behaviour of the metallic product. The thermodynamic cell voltage of the reactions should be calculated with the chemical potential of the reduced metals in the intermetallic or solid solutions rather than in the pure metallic phase. However, no experimental ternary $\mathrm{Ir}-\mathrm{Si}-\mathrm{Ti}$ phases have been reported and no predicted phase relations are available. The lack of thermodynamic data makes detailed analysis of metal deposition challenging.

The faradaic efficiency, $\eta$, of the reaction was determined from:

$$
\eta=\frac{V \cdot \rho \cdot F \cdot n}{M \cdot I \cdot t}
$$

where $V, \rho$, and $M$ are the volume, density and molar mass of the product, respectively, $n=4$ is the number of electrons in the reaction, $F$ is the Faraday constant, $I$ is the current passed during $t$, time of the potentiostatic electrolysis. The area of product and the length of electrode inside of the melt were estimated from image analysis of Figure 5. A capped, cylindrical shell geometry was assumed for the deposition volume calculations. The product was assumed homogeneous with representative composition IrTiSi, and Vegard's rule was used to obtain the molar mass and density of the product at room temperature. From this, the faradaic efficiency for the electrochemical deposition of $\mathrm{Ti}$ and $\mathrm{Si}$ from the molten oxide was estimated to be approximately $29 \% \pm 6 \%$. The uncertainty in this value was calculated 
from the uncertainties in the measured composition and volume of the deposit.

We speculate that the main contributor to the low faradaic efficiency found in this electrolysis experiment was the oxygen reduction reaction occurring in parallel with metal deposition. During electrolysis, oxygen bubbles could be observed rapidly streaming off the counter electrode and mixing through the molten electrolyte droplet. This oxygen could then be reduced at the working electrode, and thus lower the current efficiency. While we could observe oxygen in the inert gas purge stream using an inline oxygen sensor, the measurements were not accurate enough to confirm that some of the oxygen evolved at the counter electrode was subsequently reduced at the working electrode.

The proposed electrochemical reaction mechanism consists of an initial electron transfer reaction followed by surface alloy reaction and diffusion, including any consequent new phase formation. The initial electron transfer reaction can be controlled by the imposed potential (see Figure 2), while the following phenomena are successive non-electrochemical steps. The reduced metal dissolves in the surface of the iridium WE creating a chemical potential gradient that drives solid state diffusion, lowering the activity of the deposited metal towards the thermodynamically stable state of the alloy. A similar mechanism was proposed by Gao et al. [10] in the recovery of iron from a silicate melt using an Ir WE. Alloying of the metal produced on a platinum-group metal electrode has been observed before with oxide melts $[10,17,29]$.

\section{Conclusions}

A three-electrode cell configuration using the pendant droplet technique was used to investigate the electrochemical behaviour of $\mathrm{TiO}_{2}-\mathrm{SiO}_{2}-\mathrm{Al}_{2} \mathrm{O}_{3}-\mathrm{MgO}-\mathrm{CaO}$ slag. Thermodynamic predictions from FactSage were in agreement with phase relations from DSC and high temperature XRD measurements. This validated the use of thermochemical data for the slag in FactSage in the composition and temperature range of interest. Cyclic voltammetry and potentiostatic electrolysis experiments were performed to investigate the reduction process of the electroactive species in the melt. Oxygen gas evolution was observed during the electrochemical measurements, and the post-experiment microscopy analysis confirmed the reduction of metal ions from the melt. An initial electron transfer reaction followed by surface alloy reaction and diffusion is the mechanism proposed to describe the formation of the ternary $\mathrm{Ir}-\mathrm{Ti}-\mathrm{Si}$ phases that formed during electrolysis. The results presented confirm that the electrochemical recovery of metals from molten Ti-bearing slags is feasible. The temperature requirements on electrodes for these experiments introduce additional challenges when characterizing the reduction products and highlight the lack of thermochemical data for Pt-group alloys. Overall, this work shows the importance of containerless methods to enable the study of the physicalchemical properties of molten oxides at ultra-high temperatures.

\section{Acknowledgements}

The authors wish to acknowledge contributions from Dr. Ian Brown and Dr. Yaodong Yia in the sample preparation. This research was undertaken on the Powder Diffraction beamline at the Australian Synchrotron, part of ANSTO. This research was funded by NZ Ministry of Business, Innovation and Employment (MBIE) under the contract CONT46287-CRFSI-UOC.

\section{References}

[1] D. R. Sadoway, New opportunities for metals extraction and waste treatment by electrochemical processing in molten salts, Journal of Materials Research 10 (1995) 487-492.

[2] A. Allanore, Electrochemical engineering of anodic oxygen evolution in molten oxides, Electrochimica Acta 110 (2013) $587-592$.

[3] A. Y. Ilyushechkin, M. A. Duchesne, S. S. Hla, A. Macchi, E. J. Anthony, Interactions of vanadium-rich slags with crucible materials during viscosity measurements, Journal of Materials Science 48 (2013) 1053-1066.

[4] A. Allanore, Features and challenges of molten oxide electrolytes for metal extraction, Journal of The Electrochemical Society 162 (2015) E13-E22.

[5] C. Bataille, M. Ahman, K. Neuhoff, L. J. Nilsson, M. Fischedick, S. Lechtenbohmer, B. Solano-Rodriquez, A. Denis-Ryan, S. Stiebert, H. Waisman, O. Sartor, S. Rahbar, A review of technology and policy deep decarbonization pathway options for making energy-intensive industry production consistent with the paris agreement, Journal of Cleaner Production 187 (2018) 960 - 973. 
[6] U.S. Geological Survey, USGS Mineral Commodity Summaries 2019, Technical Report, 2019. URL: https://www . usgs . gov/centers/ nmic/mineral-commodity-summaries.

[7] D. Wang, A. J. Gmitter, D. R. Sadoway, Production of oxygen gas and liquid metal by electrochemical decomposition of molten iron oxide, Journal of the Electrochemical Society 158 (2011) E51-E54.

[8] J. Wiencke, H. Lavelaine, P.-J. Panteix, C. Petitjean, C. Rapin, Electrolysis of iron in a molten oxide electrolyte, Journal of Applied Electrochemistry 48 (2018) 115-126.

[9] A. Ducret, D. Khetpal, D. R. Sadoway, Electrical conductivity and transference number measurements of $\mathrm{FeO}-\mathrm{CaO}-\mathrm{MgO}-\mathrm{SiO}{ }_{2}$ melts, ECS Proceedings Volumes 19 (2002) 347-353.

[10] Y. Gao, C. Yang, C. Zhang, Q. Qin, G. Z. Chen, Magnesia-stabilised zirconia solid electrolyte assisted electrochemical investigation of iron ions in a $\mathrm{SiO}_{2}-\mathrm{CaO}-\mathrm{MgO}-\mathrm{Al}_{2} \mathrm{O}_{3}$ molten slag at $1723 \mathrm{~K}$, Phys. Chem. Chem. Phys. 19 (2017) 15876-15890.

[11] Slag Atlas, $2^{\text {nd }}$ ed., Verlag Stahleisen, Düsseldorf, 1995.

[12] H. Jiao, D. Tian, S. Wang, J. Zhu, S. Jiao, Direct preparation of titanium alloys from Ti-bearing blast furnace slag, Journal of The Electrochemical Society 164 (2017) D511-D516.

[13] B. Lin, H. Wang, X. Zhu, Q. Liao, B. Ding, Crystallization properties of molten blast furnace slag at different cooling rates, Applied Thermal Engineering 96 (2016) $432-440$.

[14] United Nations, The Sustainable Development Goals Report 2019, Technical Report, 2019. URL: https://www.un-ilibrary.org/ content/publication/55eb9109-en.

[15] S. Martin-Treceno, C. Bishop, A. Marshall, M. Watson, Value extraction from waste in the steelmaking industry, in: Chemeca 2018, Institution of Chemical Engineers, Queenstown, NZ, 2018, pp. 28.1-28.9.

[16] L. Sibille, J. Dominguez, Joule-heated molten regolith electrolysis reactor concepts for oxygen and metals production on the moon and mars, in: 50th AIAA Aerospace Sciences Meeting including the New Horizons Forum and Aerospace Exposition, 2012, p. 639.

[17] B. R. Nakanishi, A. Allanore, Electrochemical study of a pendant molten alumina droplet and its application for thermodynamic property measurements of Al-Ir, Journal of The Electrochemical Society 164 (2017) E460-E471.

[18] C. Bale, E. Belisle, P. Chartrand, S. Decterov, G. Eriksson, A. Gheribi, K. Hack, I.-H. Jung, Y.-B. Kang, J. Melancon, A. Pelton, S. Petersen, C. Robelin, J. Sangster, P. Spencer, M.-A. V. Ende, Factsage thermochemical software and databases, 2010 - 2016, Calphad 54 (2016) 35 53.

[19] B. R. Nakanishi, A. Allanore, Electrochemical investigation of molten lanthanum-yttrium oxide for selective liquid rare-earth metal extraction, Journal of The Electrochemical Society 166 (2019) E420-E428.

[20] M. Wu, A. H. Caldwell, A. Allanore, Surface tension of high temperature liquids evaluation with a thermal imaging furnace, in: J. Nakano, P. C. Pistorius, C. Tamerler, H. Yasuda, Z. Zhang, N. Dogan, W. Wang, N. Saito, B. Webler (Eds.), Advanced Real Time Imaging II, Springer International Publishing, Cham, 2019, pp. 33-41.

[21] D. Bandyopadhyay, The Ti-Si-C system (titanium-silicon-carbon), Journal of Phase Equilibria and Diffusion 25 (2004) $415-420$.

[22] A. Caldwell, E. Lai, A. Gmitter, A. Allanore, Influence of mass transfer and electrolyte composition on anodic oxygen evolution in molten oxides, Electrochimica Acta 219 (2016) 178 - 186.

[23] H. Kahlert, Reference Electrodes, Springer Berlin Heidelberg, Berlin, Heidelberg, 2010, pp. 291-308.

[24] Y. Hemberger, C. Berthold, K. G. Nickel, Wetting and corrosion of yttria stabilized zirconia by molten slags, Journal of the European Ceramic Society 32 (2012) 2859 - 2866. Special Issue: ECerS XII, 12th Conference of the European Ceramic Society.

[25] F. G. K. Baucke, Reference Electrodes in Oxidic Glass Melts, Springer Berlin Heidelberg, Berlin, Heidelberg, 2013 , pp. $229-241$.

[26] M. Luisi, B. Wilthan, G. Pottlacher, Influence of purge gas and spacers on uncertainty of high-temperature heat flux dsc measurements, Journal of Thermal Analysis \& Calorimetry 119 (2015) 2329-2334.

[27] H. Kim, J. Paramore, A. Allanore, D. R. Sadoway, Electrolysis of molten iron oxide with an iridium anode: The role of electrolyte basicity, Journal of the Electrochemical Society 158 (2011) E101-E105.

[28] J. L. Murray, The Ir-Ti (iridium- titanium) system, Bulletin of Alloy Phase Diagrams 3 (1982) 205-211.

[29] K. Kawamura, T. Yokokawa, Linear sweep voltammetry of $\mathrm{Pb}^{2+} / \mathrm{Pb}^{0}$ in oxide melts: Model and simulation of electrode process, Journal of The Electrochemical Society 135 (1988) 1447-1451. 


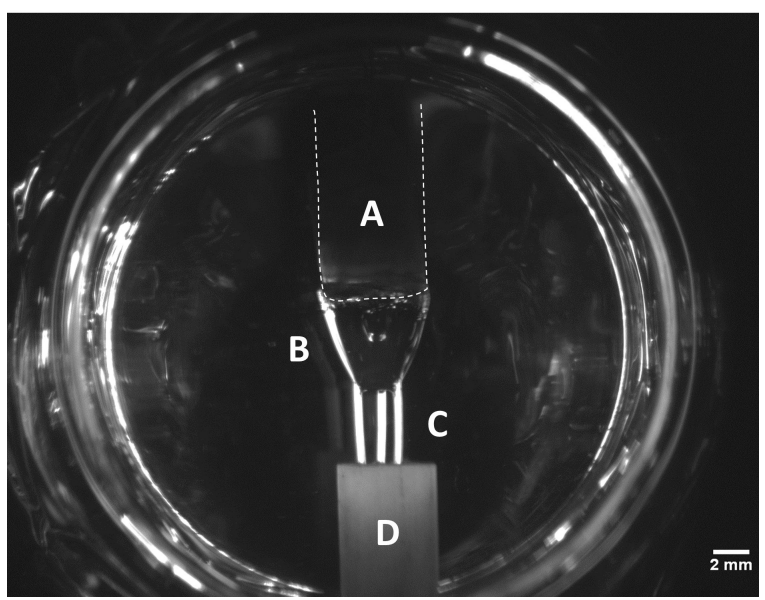

Figure 1: Optical image of the electrochemical cell: (A) solid sample rod, (B) molten pendant droplet, (C) electrodes, (D) electrode probe. 


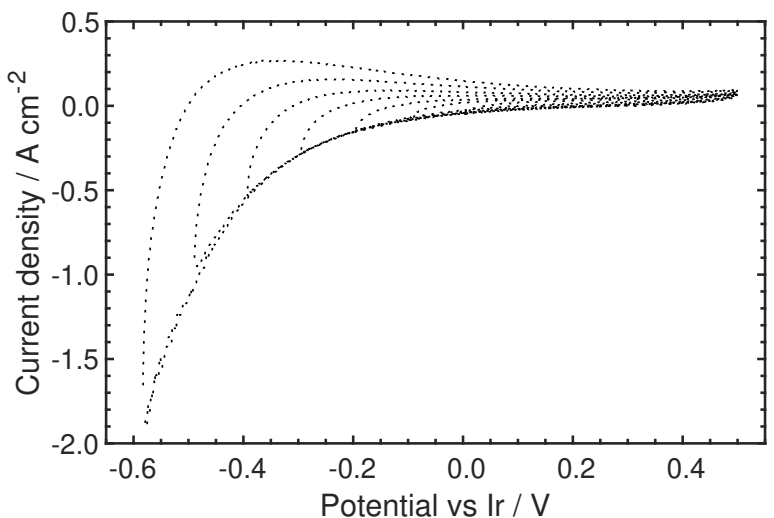

Figure 2: Cyclic voltammograms of Slag $C$ at $1903 \mathrm{~K}$. The upper potential limit was $0.5 \mathrm{~V}$ vs Ir for all measurements and the lower potential limit was varied across $0 \vee,-0.1 \vee,-0.2 \vee,-0.3 \vee,-0.4 \mathrm{~V},-0.5 \vee$ and $-0.6 \mathrm{~V}$. Scan rate: $1 \mathrm{~V} \mathrm{~s}^{-1}$. 


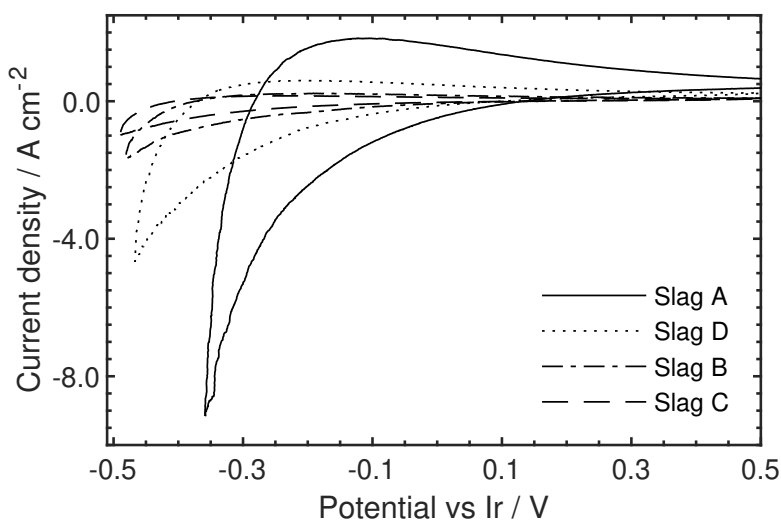

Figure 3: Cyclic voltammograms of the four slag compositions at $1903 \mathrm{~K}_{\text {with a }} 1 \mathrm{~V} \mathrm{~s}^{-1}$ scan rate. The upper and lower potential limits were $0.5 \mathrm{~V}$ and $-0.5 \mathrm{~V}$ vs Ir. 


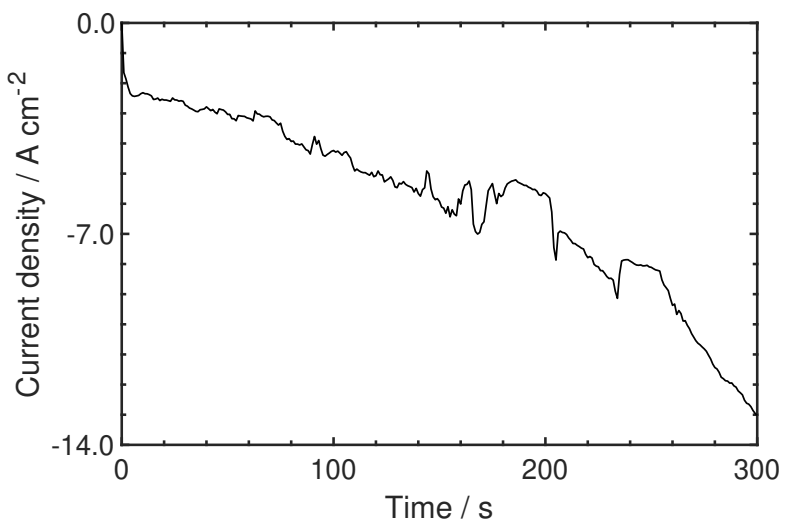

Figure 4: Current density vs time plot recorded from a potentiostatic electrolysis experiment for Slag D. Potential held at $-0.6 \mathrm{~V}$ for $300 \mathrm{~s}$. T: $1903 \mathrm{~K}$. Electrode area: $0.035 \mathrm{~cm}^{2}$. 

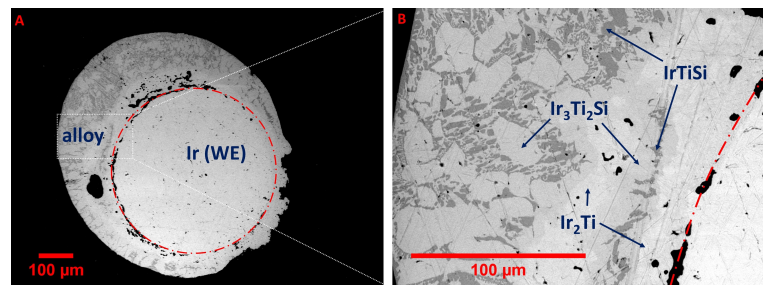

Figure 5: Back-scatter electron (BSE) images of the quenched iridium working electrode after the potentiostatic electrolysis experiment reported in Figure 4. (A) is a complete cross section with the pure iridium electrode area delimited by a red circumference. (B) is the higher magnification of left portion of product with Ir-Si-Ti phases labelled. 